\title{
Sediment storage and morphology of the Yalu Tsangpo valley due to uneven uplift of the Himalaya
}

\author{
WANG ZhaoYin ${ }^{1 *}$, YU GuoAn ${ }^{2}$, WANG XuZhao ${ }^{3}$, Charles S. MELCHING ${ }^{4} \&$ LIU Le $^{1}$ \\ ${ }^{1}$ State Key Laboratory of Hydro-Science and Engineering, Tsinghua University, Beijing 100084, China; \\ ${ }^{2}$ Key Laboratory of Water Cycle and Related Land Surface Processes, Institute of Geographic Sciences and Natural Resources Research, \\ Chinese Academy of Sciences, Beijing 100101, China; \\ ${ }^{3}$ Beijing Institute of Geology for Mineral Resources, Beijing 100012, China; \\ ${ }^{4}$ Environmental Consultant, Greenfield, WI, USA
}

Received September 1, 2014; accepted April 13, 2015; published online May 28, 2015

\begin{abstract}
The fluvial process of the Yalu Tsangpo River occurs concurrently with the uplift of the Qinghai-Tibet Plateau. Therefore, the river exhibits unique features in morphology and sediment deposition. Field investigations were performed from 2009-2011 and the depth of the interface between the sediment deposits and bed rock was detected with an electromagnetic imaging system (EH4) at 29 cross sections. Sediment deposits were sampled along the Yalu Tsangpo valley from Xietongmen to the Yalu Tsangpo Canyon. The results show that a huge amount of sediment has been deposited in four wide valley sections because the uplift rate in these sections was lower than that in the downstream gorge sections over the past million years. About 518 billion $\mathrm{m}^{3}$ of gravel and sand have been stored in the high mountain river valleys, which has changed the V-shaped mountain river valley into a U-shaped wide river valley in the four sections. In the sections with high uplift rates the river bed is incised and has formed gorges and the Yalu Tsangpo Canyon.
\end{abstract}

Yalu Tsangpo River, sediment deposits, uneven uplift, himalaya, wide valley

Citation: Wang Z Y, Yu G A, Wang X Z, Melching C S, Liu L. 2015. Sediment storage and morphology of the Yalu Tsangpo valley due to uneven uplift of the Himalaya. Science China: Earth Sciences, 58: 1440-1445, doi: 10.1007/s11430-015-5113-7

According to the British Geological Survey, the Indian Plate moves northward at a rate of $50 \mathrm{~mm} / \mathrm{a}$ and collides with the Eurasian Plate, resulting in the uplift of the Himalaya Mountains and the Qinghai-Tibet Plateau (Zhang et al., 2004; Royden et al., 2008; Chen and Gavin, 2008). Uplift of the Qinghai-Tibet Plateau has been accompanied by the development of a series of large strike-slip faults and associated extensional normal faulting with slip rates on these faults averaging 1-20 mm/a (Tapponnier et al., 2001). Similar results have been obtained by other scientists (Yin and Harrison, 2000). Many researchers have reported that the

*Corresponding author (email: zywang@tsinghua.edu.cn) tectonic motion and the uplift of the plateau are accelerating (Harvey and Wells, 1987; Coleman and Hodges, 1995; Chung et al., 1998; Royden et al., 2008). The Chinese Earthquake Bureau measured the current average rate of rise of the Himalaya Mountains at about $21 \mathrm{~mm} / \mathrm{a}$. The uplift of the plateau essentially created the macro-relief of the Yalu Tsangpo Basin. After the formation of the stream network the continuous tectonic motion and uplift of the plateau have been affecting the fluvial process and reshaping the river morphology, particularly because the uplift rate of the plateau has been uneven along the Yalu Tsangpo valley from west to east (TECAS, 1984; Hallet and Molnar, 2001; Li et al., 2006).

The Yalu Tsangpo River (Tsangpo means river in Tibet- 
an) is an upstream tributary of the Brahmaputra River. The river originates from the Jimayangzong Glacier on the northern slope of the Himalaya Mountains and flows eastward for about $1600 \mathrm{~km}$ before pouring into the Grand Canyon of the Yalu Tsangpo (Yalu Tsangpo Canyon), which is located from Pai to Pasighat (Figure 1). Different from any other rivers the fluvial process of the Yalu Tsangpo occurs concurrently with the uplift of the Himalaya Mountains and Qinghai-Tibet Plateau. Therefore, the river exhibits unique features in morphology and sediment movement (Wang and Zhang, 2012). The river consists of alternating sections of wide valleys and gorges. The wide valley sections have braided and anastomosing channels, gentle bed gradient, and thick alluvial deposits. In contrast, the gorge sections exhibit single, straight, and deeply incised meandering channels with a steep gradient, rock channel bed, and several terraces (TECAS, 1983, 1984; Hallet and Molnar, 2001; Li et al., 2006; Zhang, 1998).

There is a huge amount of sediment deposited in the wide valley sections, which consists of gravel and sand. For geological investigations core samples were taken in recent years from six wells with depths varying from 20 to $140 \mathrm{~m}$. In three wide valley sections with a width of about $1500 \mathrm{~m}$ the samples from depths of $120,140,105$, and $111 \mathrm{~m}$ consist mainly of gravel mixed with sand in the interstices of the gravel (He et al., 2008). In the gorge sections, however, the channel bed consists of bed rock and only a shallow layer of boulders covers the rocky bed.

This paper studies the river morphology and sediment storage and their relation with the tectonic motion in the Yalu Tsangpo valley. Field investigations were done, sediment samples were taken, and the depth of the interface between the bed rock and the sediment deposit was measured in 2009-2011. It is found that the rate of uplift of the river valley, following the uplift of the Himalaya Mountains, is uneven from west to east, which has resulted in a huge amount of gravel storage and lotus-root shaped river valley.

\section{Research methods}

Twenty-nine cross sections were selected for detection of the bed rock depth and sampling of sediment deposition along a 1,000 km long reach of the Yalu Tsangpo valley from Xietongmen to the Yalu Tsangpo Canyon. The STRATAGEM EH4 electromagnetic imaging system, jointly produced by Geometrics, Inc. and Electromagnetic Instruments, Inc. (EMI), was used to measure the depth of the interface of bed rock and the sediment deposits. There is a sharp change of the electromagnetic signal at the interface. The detected depth of sediment deposits measured with the STRATAGEM EH4 was compared with the data from core boring and the instrument was found to have a relative error of less than $10 \%$. In field investigations several shallow deposit profiles were found at gravel mining sites and highway and bridge construction sites, where deposit samples were taken, or the depth of the bed rock surface was estimated.

A Contour laser range meter made by Kustom Signals Inc., with an accuracy of $0.1 \mathrm{~m}$ and a measurement range of $2000 \mathrm{~m}$, was used for distance measurement from the banks along the cross sections. A Meridian color Global Positioning System (GPS) made by Magellan was used to measure elevation and position. This measurement has a maximum error of $1 \mathrm{~m}$. Shuttle Radar Topography Mission from the U.S. National Aeronautics and Space Administration (NASA) provided the basic digital elevation model (DEM) terrain data (SRTM3, resolution $90 \mathrm{~m}$ ). ArcGIS was used to extract longitudinal profiles and river channel gradients. Google Earth satellite images were used to examine planform features of fluvial morphology and river patterns. The flow discharge, velocity, sediment concentration, and suspended sediment load data at Daqiao (Lhasa), Nugsha $(88$ $\mathrm{km}$ downstream of Shigatse), and Nuxia (Linzhi) hydrological stations were collected in the 1960s, 1980s, and 1990s. The sediment deposits were sampled from depths of $0.5-4$ $\mathrm{m}$ in the wide valley sections. Size distributions of sediment were obtained by sieving the samples.

\section{Results and discussion}

Figure 1(a) shows the stream network of the Yalu Tsangpo River. The drainage area is elongated in the east-west direction and confined in the north-south direction because the northward movement of the Indian Plate squeezed the basin and confined its development in the north and south directions. The stream network consists of 57100 first-order streams and the river becomes a 9th-order stream at the Yalu Tsangpo Canyon below the confluence with the Palung Tsangpo River. The studied reach of the river is from Xietongmen to confluence site of Palung Tsangpo with Yalu Tsanpo, basically the upper one fourth part of the Yalu Tsangpo Canyon.

In the plan view the Yalu Tsangpo valley looks like lotus roots with gorge sections with widths of only $0.1-0.2 \mathrm{~km}$ between wide valleys with widths of $3-10 \mathrm{~km}$, as shown in Figure 1(b). The brown area in Figure 1(b) is the valley defined by the boundary of sediment deposits and the mountains, whereas the blue curves are the river channels, which are a single thread in the gorge sections but multiple threads in the wide valleys. Numerous bars and islands are formed in the wide valley sections. In the gorge sections bed rock is exposed to the water flow at many places and big boulders of $1 \mathrm{~m}$ in size or larger overlap and form step-pool sequences in the channel. Several terraces of 10-30 m high are on one side of the two banks, which implies a long period of river bed incision. In the wide valleys, however, there is a very thick layer of sediment deposits consisting of 
gravel and sand, which implies long-term aggradation.

Figure 2 shows three cross sections in the wide valleys and one cross section in a gorge section, from which the depth of the bed rock surface, or interface between the bed rock and sediment deposit, and the thickness of sediment deposit layer can be read. The locations of the four cross sections in the plan view and the longitudinal profile are shown in Figures 1(a) and 3. The channel in the non-flood season is much narrower than the valley in wide sections but almost occupies the whole valley bottom in the gorge sections. The original river valley at the cross sections was
V-shaped. Long term sediment deposition caused aggradation and resulted in flat and wide valleys, as shown for Cross Sections 5, 13, and 26 in Figure 2. The present channel is developing on the sediment deposits, and is not stable, thus migrating within the wide valleys. The river pattern in the wide valleys is braided. The floodplain is large and flat with very poor vegetation. The width of the valleys is as large as $10 \mathrm{~km}$. In the gorge sections like CS 16 the valley remains V-shaped and the river pattern is straight. Because the bed rock channel has experienced quick incision the lower part of the bank slope is steeper than upper part.

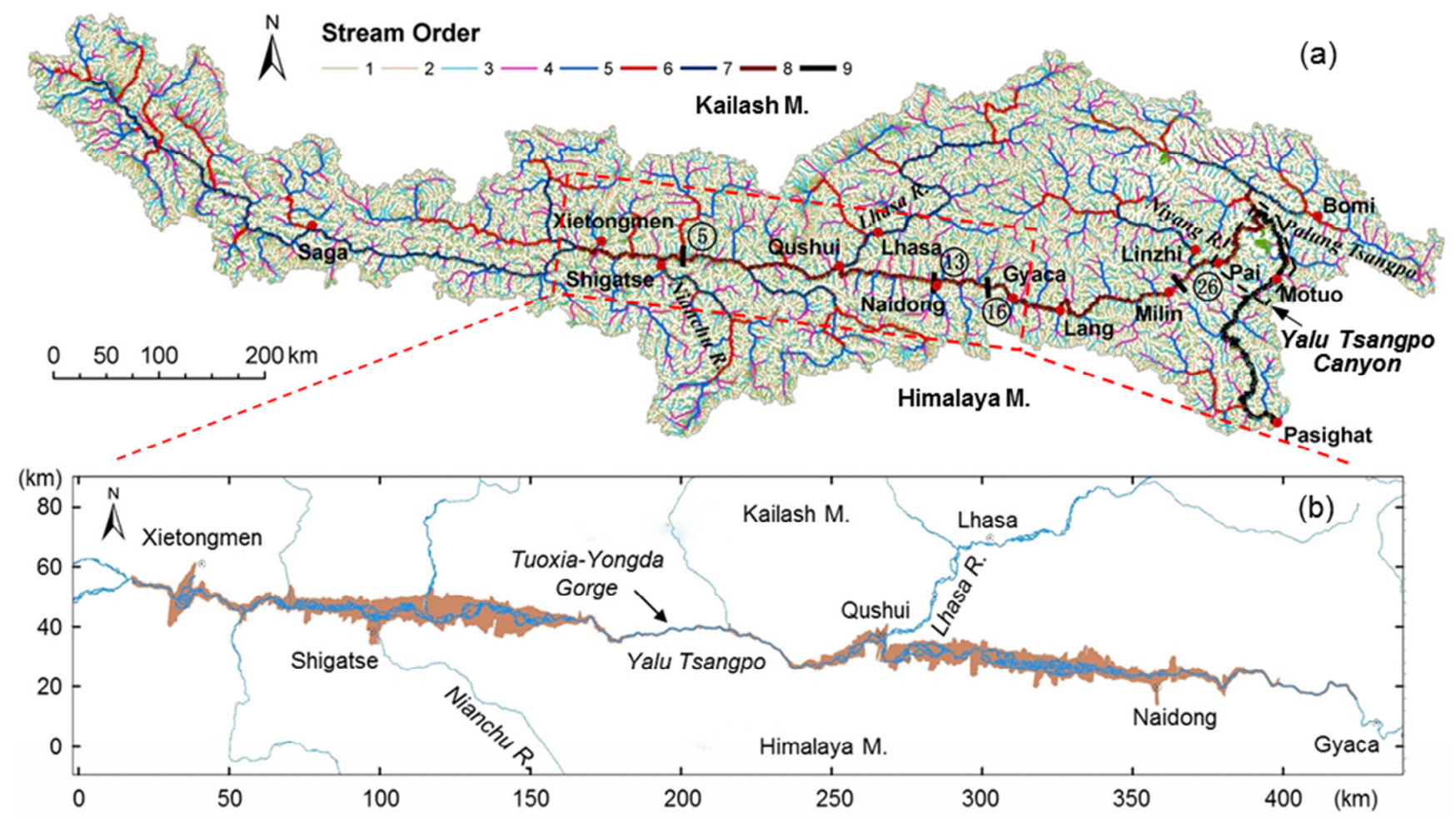

Figure 1 Stream network of the Yalu Tsangpo Basin (a), Plan view of the Yalu Tsangpo valley with gorge sections (200 m wide) between wide valleys (10 $\mathrm{km}$ wide) (b).
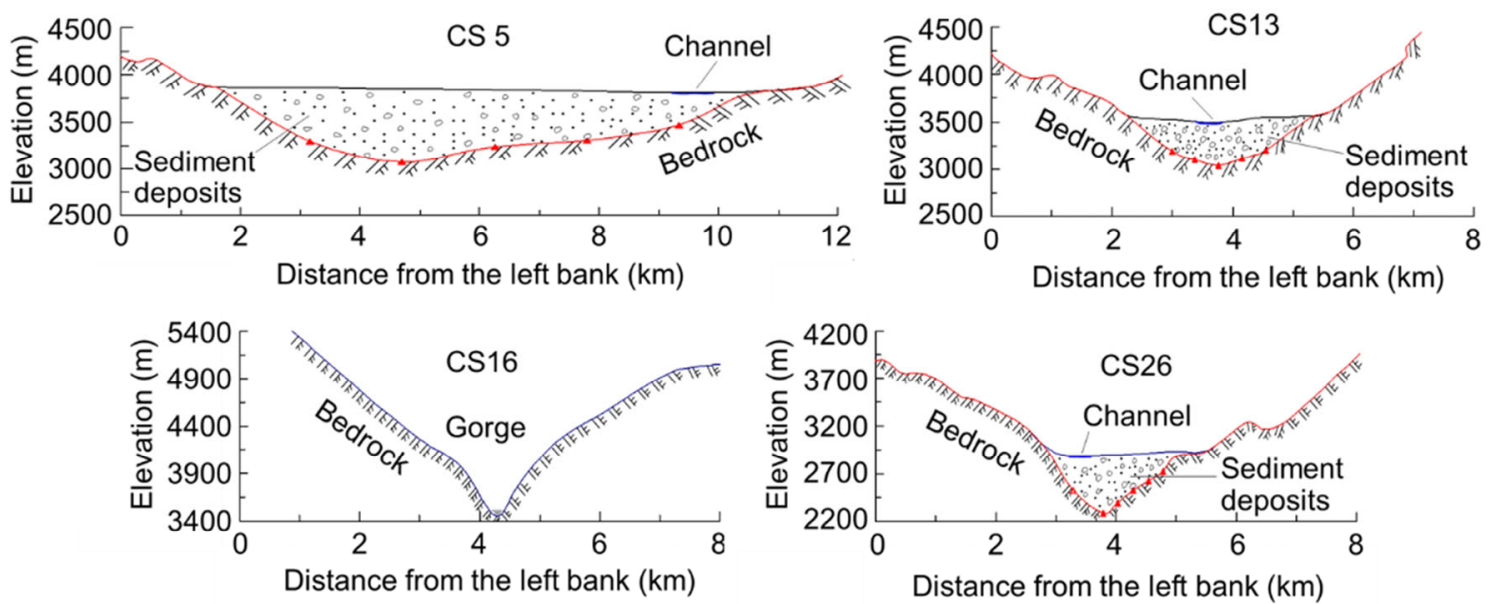

Figure 2 Four cross sections showing the present valley bed and the interface between the sediment deposits and bed rock surface. CS 5, downstream of Shigtase; CS 13, Naidong; CS 16, Zengga Gorge; CS 26, Milin. 
There is almost no sediment deposition in the gorge section, where the bed gradient and flow velocity are high. The bed rock surface is close to the channel bed and in several places the bed rock is exposed to the water flow.

Figure 3 shows the longitudinal profile of the current channel thalweg, the profile of the interface between the sediment deposit and bed rock, and the mean mountain elevation within $10 \mathrm{~km}$ of the river valley in lateral direction to river channel. The profiles of the thalweg and interface were obtained by connecting the lowest points of the current channel bed and the sediment-rock interface for the 29 measured cross sections, respectively. The points A-C in the figure are the locations of core borings. The solid triangles are the cross sections measured with the EH4. The hollow triangles are the depth of the interface from exposed rock on the channel bed and the core boring data. The bed rock surface in the gorge sections is several hundred meters higher than the interface in the upstream wide valleys and forms several huge "sediment reservoirs". Gravel and sand filled these "reservoirs" over the past million years, over which a braided fluvial river has developed. In the gorge sections the bed gradient is high and the water flow has scoured the rocky bed, which resulted in long term stream bed incision. These gorge sections become knickpoints. The three knickpoints near Saga (located upstream of Xietongmen and out of the range of Figure 3), Gyaca, and Pai were believed to indicate three stages of uplift in the Quaternary Himalayan Movements (TECAS, 1983).

On the slope of the Himalaya Mountains fluvial incision occurred in the rivers following the uplift of the mountains (Burbank et al., 1996; Lavé and Avouac, 2001). Nevertheless, a long period of sediment deposition occurred in the Yalu Tsangpo valley and a huge amount of sediment has been stored, which is very unique. The river is on the Tibetan Plateau, and the uplift of the Himalaya Mountains and the plateau does not directly increase the river bed gradient except for the Yalu Tsangpo Canyon, which is on the south slope of the plateau. Many tension faults are present across the river valley. For instance, a fault across the river valley occurred at the upper end of the Tuoxia-Yongda Gorge between the CS 7 and CS 8. The east side of the fault moved up relative to the west side. The relative movement is due to the differing uplift rates. A high rate of uplift occurred in some sections and a lower rate of uplift occurred in other sections along the river valley. The uneven uplift resulted in depressions and sediment deposited in these depressions.

Figure 4 shows the maximum depth of the sediment deposit and the width of the valley along the river from Xietongmen to the Yalu Tsangpo Canyon. Large width of the valley corresponds to large depth of the sediment deposits. This is because the sediment buried the narrow bottom of the valley and the narrow $\mathrm{V}$-shaped channel has been changed to wide U-shaped channel.

Table 1 lists the maximum depth of the sediment deposits and sedimentation volume between the cross sections. The

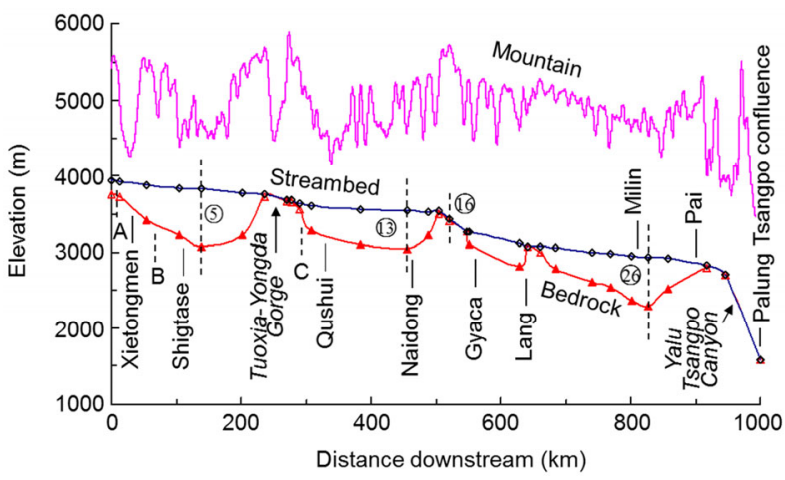

Figure 3 Longitudinal profiles of the thalweg of the present channel bed, the interface between the bed rock and sediment deposits, and the bank mountain elevation within $10 \mathrm{~km}$ of the river valley in lateral direction to river channel.

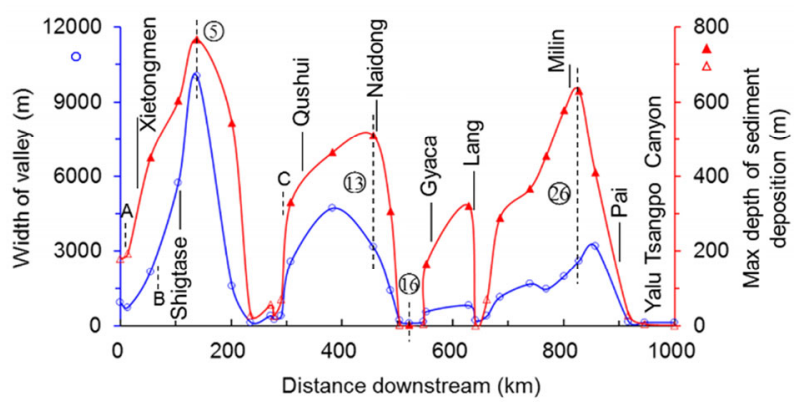

Figure 4 The maximum depth of sediment deposits and valley width along the Yalu Tsangpo River.

thickness of the sediment deposits is $400-800 \mathrm{~m}$. For each cross section the area of the sediment deposits between the valley bed surface and the sediment-rock interface can be calculated. The total volume of the sediment deposit in the $1000 \mathrm{~km}$ long river valley is obtained by summing the products by multiplying the cross sectional area of sediment deposit and the distance between the neighboring cross sections. The total volume of sediment storage in the river valley is about 518 billion $\mathrm{m}^{3}$. The average annual water runoff from 1956-2000 at Nuxia Station (Linzhi) was 60.6 billion $\mathrm{m}^{3}$ and the annual suspended sediment load (mainly fine sand) was about 30 million tons. The bed load was not measured in the Yalu Tsangpo River. Nevertheless, the bed load transportation in the Yangtze River was measured for the Three Gorges Project (Wang et al., 2007). According to these measurements the average annual bed load at the upstream end of the reservoir was about 0.4 million $\mathrm{m}^{3}$, which consists mainly of gravel and coarse sand (Han, 2009). The bed load transported from upstream of the Lijiang has been trapped by the huge Hutiaoxia Gorge landslide dam for several centuries. Therefore, the measured bed load was produced in the reach from the Lijiang to the upper end of the Three Gorges Reservoir, of which the length of the river reach and effective erosion area are similar to those of the Yalu Tsangpo River. Estimated with the same annual rate 
Table 1 Volume of sediment storage between the cross sections of the Yalu Tsangpo valley

\begin{tabular}{|c|c|c|c|c|c|c|}
\hline $\mathrm{CS}$ & $L(\mathrm{~km})^{\mathrm{a})}$ & $S(\mathrm{~km})^{\mathrm{b})}$ & $W(\mathrm{~m})^{\mathrm{c})}$ & $H_{m}(\mathrm{~m})^{\mathrm{d})}$ & $\left.V\left(10^{9} \mathrm{~m}^{3}\right)^{\mathrm{e}}\right)$ & Note \\
\hline 1 & 0.00 & 0.00 & 730 & 193 & 9.497 & \multirow{10}{*}{$\begin{array}{c}\text { Tuoxia-Yongda } \\
\text { Gorge }\end{array}$} \\
\hline 2 & 40.76 & 40.76 & 2170 & 450 & 53.043 & \\
\hline 3 & 50.77 & 91.53 & 5760 & 604 & 90.043 & \\
\hline 4 & 33.23 & 124.76 & 10040 & 768 & 120.695 & \\
\hline 5 & 63.28 & 188.04 & 1590 & 544 & 4.198 & \\
\hline 6 & 33.91 & 221.95 & 140 & 28 & 0.202 & \\
\hline 7 & 35.70 & 257.65 & 400 & 55 & 0.061 & \\
\hline 8 & 3.10 & 260.75 & 1520 & 27 & 0.071 & \\
\hline 9 & 3.29 & 264.04 & 260 & 70 & 0.111 & \\
\hline 10 & 13.10 & 277.14 & 390 & 35 & 2.334 & \\
\hline 11 & 17.21 & 294.35 & 2570 & 332 & 54.932 & \\
\hline 12 & 75.58 & 369.93 & 4730 & 465 & 70.333 & \\
\hline 13 & 73.05 & 442.98 & 3170 & 510 & 14.678 & \\
\hline 14 & 31.47 & 474.45 & 1400 & 307 & 1.081 & \\
\hline 15 & 16.31 & 490.76 & 270 & 11 & 0.049 & \multirow{3}{*}{$\begin{array}{c}\text { Upper Gyaca } \\
\text { Gorge }\end{array}$} \\
\hline 16 & 30.54 & 521.30 & 106 & 3 & 0.243 & \\
\hline 17 & 12.53 & 533.83 & 240 & 7 & 0.082 & \\
\hline 18 & 4.74 & 538.57 & 560 & 166 & 6.419 & \\
\hline 19 & 77.31 & 615.88 & 804 & 321 & 0.488 & \\
\hline 20 & 11.83 & 627.71 & 208 & 5 & 0.062 & \multirow{2}{*}{ Lang Gorge } \\
\hline 21 & 20.62 & 648.33 & 394 & 35 & 1.433 & \\
\hline 22 & 23.06 & 671.39 & 1140 & 289 & 12.650 & \\
\hline 23 & 54.86 & 726.25 & 1670 & 368 & 9.312 & \\
\hline 24 & 28.92 & 755.17 & 1460 & 456 & 14.512 & \\
\hline 25 & 32.56 & 787.73 & 1990 & 578 & 18.442 & \\
\hline 26 & 26.55 & 814.28 & 2610 & 630 & 22.117 & \\
\hline 27 & 29.24 & 843.52 & 3200 & 412 & 11.181 & \\
\hline 28 & 60.28 & 903.80 & 167 & 29 & 0.038 & \multirow{3}{*}{$\begin{array}{c}\text { Yalu Tsangpo } \\
\text { Canyon }\end{array}$} \\
\hline 29 & 29.03 & 932.83 & 139 & 5 & 0.011 & \\
\hline 30 & 53.57 & 986.40 & 130 & 1 & & \\
\hline sum & & & & & 518.3 & \\
\hline
\end{tabular}

a) Distance between cross sections; b) accumulated distance from cross section 1 (CS 1); c) width of valley bottom; d) maxium depth of sediment deposition of the cross section; e) volume of sediment storage between cross sections. the total volume of 518 billion $\mathrm{m}^{3}$ was stored in a period of 1.2 million years. In other words, the river continuously stored sediment while the uneven uplift of the Qinghai-Tibet plateau occurred over the last million years. Up to now, a huge amount of sediment, which created $5000 \mathrm{~km}^{2}$ of plains with maximum depths of 350-800 m of sediment, has been stored in the wide river valley sections.

The Tuoxia-Yongda, upper Gyaca, Lang, and Yalu Tsangpo Canyon sections have been rising faster than the Shigatse, Qushui-Naidong, Gyaca, and Milin sections, as shown in Figure 3. Fluvial processes have concurrently occurred with the geological processes. Sediment has been continuously deposited in the slowly-rising sections. In the meantime channel bed incision occurred in the fast-rising sections.

Figure 5 shows the size distributions and pictures of sediment deposits at the wide valley section CS 5 and Gyaca gorge section CS16. The size distributions of sediment deposits at the two wide valley sections are almost the same. The sediment consists of gravel (about 75\%) and sand (about 25\%). Indeed, from the samples taken from the core boring and shallow sediment profiles at sediment mining sites the sediment composition differs little at different depths and different locations in the wide valley sections. This fact implies that the difference in the uplift rate occurred over a very long period of time, which formed high gradient sections and low gradient sections rather than "dams" and "lakes". Gravel might transport through the river channel but mostly deposited in the low gradient sections. Following further uplift the low gradient sections due to lower uplift rates continuously stored gravel and sand. Finally, the low uplift rate sections stored a huge amount of gravel and sand and formed very wide valleys. This is different from the formation of reservoirs by dam construction, in which sediment deposition in the reservoir exhibits clear sorting features: clay and silt deposit near the dams, sand in the middle, and gravel in the upper end of the reservoirs.

On the margin of the Qinghai-Tibet Plateau many rivers have experienced a long period of continuous bed incision
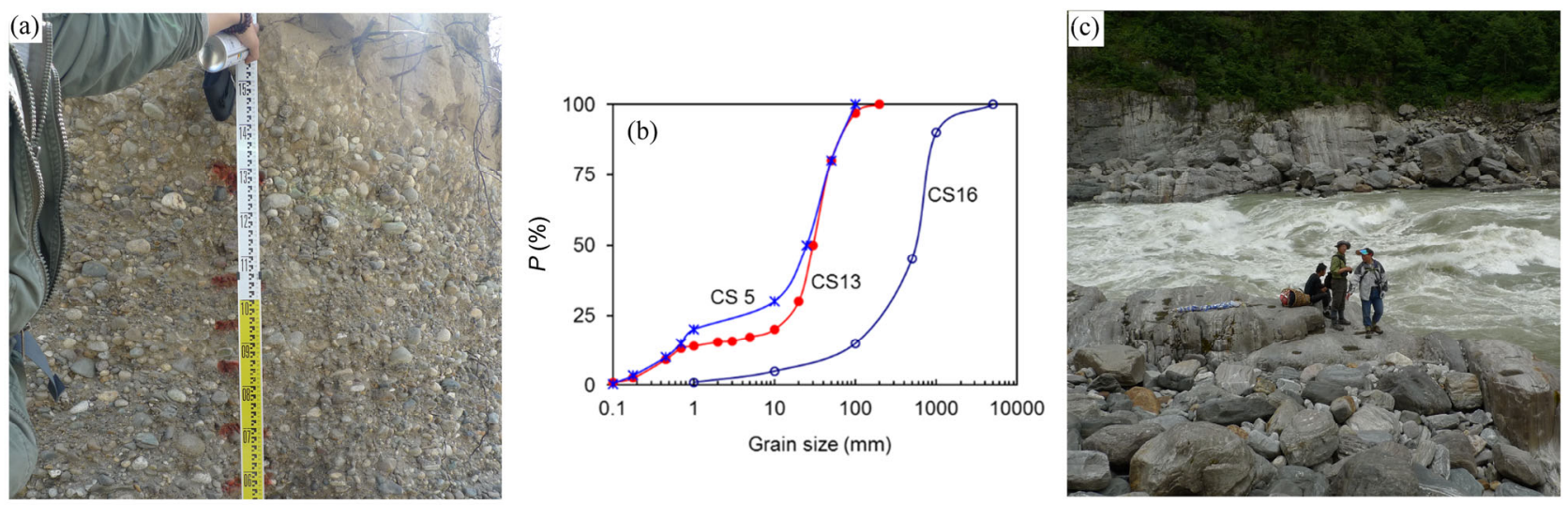

Figure 5 There is a $700 \mathrm{~m}$ thick layer of gravel and fine sand at CS 5 (wide valley section) (a), size distribution of sediment deposits at CS 5 , CS 13, and CS 16 (b), boulders and cobbles and exposed bed rock at CS 16 (gorge section) (c). $P$, the percentage of particles finer than a given size. 
because the uplift of the plateau has been increasing the stream bed gradient. The long term sedimentation in the Yalu Tsangpo valley is very different from the rivers on the margin of the plateau. As shown in Figure 6, uneven uplift of the plateau resulted in sediment storage. A high rate of uplift occurred in some sections and a lower rate of uplift occurred in other sections along the river valley. The uneven uplift resulted in several low gradient sections and sediment deposited in these sections. Gravel might transport through the river channel but it mostly deposited in the low gradient sections. Following further uplift the low gradient sections continuously stored gravel and sand. Finally, the low gradient sections stored a huge amount of gravel and sand and formed very wide valleys. In the meantime channel bed incision occurred in the high gradient sections, where a high rate of uplift occurred. After a long period of time, the bed rock in the Shigatse, Qushui-Naidong, Gyaca, and Milin sections has been buried underneath a very thick layer of sediment deposits and the valleys have become very wide. On the other hand, the Tuoxia-Yongda, upper Gyaca, Lang, and Yalu Tsangpo Canyon sections have become deeply incised gorges. Through this process the Yalu Tsangpo Canyon formed, in which the water falls $2000 \mathrm{~m}$ in a $100 \mathrm{~km}$ long gorge section.

\section{Conclusions}

The rising Himalaya Mountains and Qinghai-Tibet Plateau have raised the Yalu Tsangpo valley. However, the rate of uplift is different along the river, with high rates occurring in the gorge sections and lower rates in the wide valley sections. Sedimentation has occurred in the low uplift rate sections and stream bed incision has occurred in the high uplift sections. The fluvial processes have concurrently occurred with the tectonic processes. As a result a huge amount of

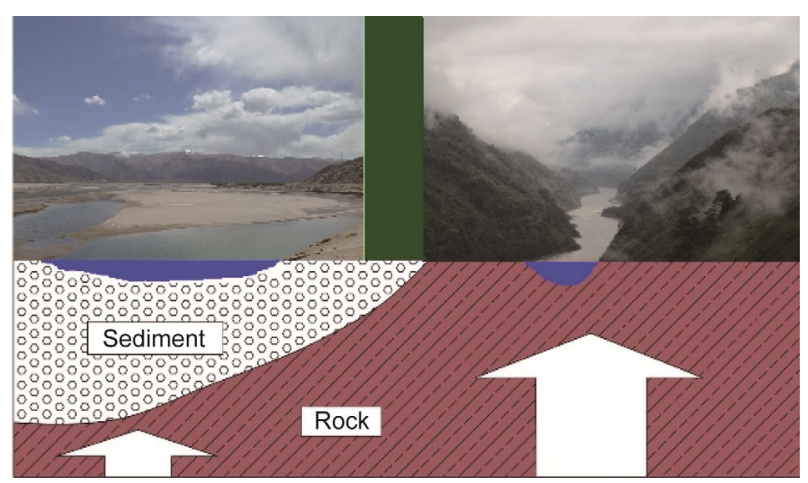

Figure 6 Gravel and sand were continuously stored in depressions resulting from uneven uplift and the river valley becomes very wide (left), and incision occurred in the reaches with a high rate of uplift, which resulted in a narrow and V-shape valley covered with a thin layer of boulders and cobbles (right). sediment has been stored in four low uplift sections and changed the $\mathrm{V}$-shaped mountain river valley into four U-shaped wide valley sections. The thickness of the sediment deposits is $300-800 \mathrm{~m}$. About 518 billion $\mathrm{m}^{3}$ of gravel and sand have been stored in the high mountain river valleys over the last million years, which resulted in the lotus root shape of the Yalu Tsangpo valley.

The study was supported by the National Natural Science Foundation of China (Grant Nos. 41071001, 41001008) and the Ministry of Science and Technology of China (Grant No. 2011DFA20820).

Burbank D W, Leland J, Fielding E, et al. 1996. Bedrock incision, rock uplift and threshold hillslopes in the northwestern Himalayas. Nature, 379: 505-510

Chen J, Gavin H. 2008. Finite Fault Model of the May 12, $2008 M_{\mathrm{w}} 7.9$ Eastern Sichuan, China. United States Geological Survey-National Earthquake Information Center. http://earthquake.usgs.gov/, Retrieved 2008-05-15

Chung S L, Lo C H, Lee T Y, et al. 1998. Diachronous uplift of the Tibetan Plateau starting $40 \mathrm{Myr}$ ago. Nature, 394: 769-774

Coleman M, Hodges K. 1995. Evidence for Tibetan Plateau uplift before $14 \mathrm{Myr}$ ago from a new minimum age for east-west extension. Nature, 3742: 49-52

Hallet B, Molnar P. 2001. Distorted drainage basins as markers of crustal strain east of the Himalaya. J Geophys Res, 106: 697-709

Han Q W. 2009. Analysis on bed load amount and research on sedimentation of Three Gorges Reservoir (in Chinese). Water Resour Hydropower Eng, 40: 44-55

Harvey A M, Wells S G. 1987. Response of quaternary fluvial systems to differential epeirogenic uplift: Aguas and Feos river systems, southeast Spain. Geology, 15: 689-693

He G, Fu Y, Li R, et al. 2008. Valley shape and sediment deposit in the major rivers in Southestern Tibet and their effect on the economic development (in Chinese). Monitoring of Hydro-science and Technology, 5

Lavé J, Avouac J P. 2001. Fluvial incision and tectonic uplift across the Himalayas of central Nepal. J Geophys Res, 106: 26561-26591

Royden L H, Burchfiel B C, van der Hilst R D. 2008. The geological evolution of the Tibetan Plateau. Science, 321: 1054-1058

Li Y L, Wang C S, Wang M, et al. 2006. Morphological features of river valleys in the source region of the Yangtze River, northern Tibet, and their response to neotectonic movement (in Chinese). Geol China, 33: 374-382

Tapponnier P, Xu Z Q, Roger F, et al. 2001. Oblique stepwise rise and growth of the Tibet Plateau. Science, 294: 1671-1677

Tibetan Expedition team of Chinese Academy of Sciences (TECAS). 1983. Tibetan geomorphology (in Chinese). Beijing: Science Press

Tibetan Expedition team of Chinese Academy of Sciences (TECAS). 1984. Rivers and lakes in Tibet (in Chinese). Beijing: Science Press

Wang Z Y, Li Y T, He Y P. 2007. Sediment budget of the Yangtze River. Water Resour Res, 43: 1-14

Wang Z Y, Zhang K. 2012. Principle of equivalency of bed structures and bed load motion. Int J Sediment Res, 27: 288-305

Yin A, Harrison T M. 2000. Geologic evolution of the Himalayan-Tibetan orogen. Annu Rev Earth Planet Sci, 28: 211-280

Zhang D D. 1998. Geomorphological problems of the middle reaches of the Tsangpo river, Tibet. Earth Surf Process Landf, 23: 889-903

Zhang P Z, Shen Z K, Wang M, et al. 2004. Continuous deformation of the Tibetan Plateau from global positioning system data. Geology, 32: 809-812 